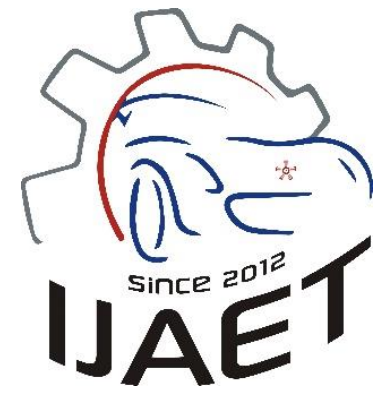

e-ISSN: 2146 - 9067

International Journal of Automotive

Engineering and Technologies

journal homepage:

https://dergipark.org.tr/en/pub/ijaet

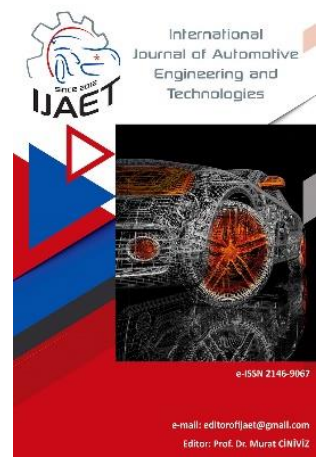

Original Research Article

\title{
Investigation of effects of boron additives on performance of cam mechanisms
}

\begin{tabular}{|c|c|}
\hline & Hasan Baş ${ }^{1, *}$ \\
\hline *Department of Mecha & ngineering, Faculty of Engineering, Karadeniz Technical University, Trab \\
\hline ARTICLE INFO & ABSTRACT \\
\hline 1. $0000-0002-5653-3813$ & The use of additives in the contacting surfaces is essential for the formation \\
\hline Doi: $10.18245 /$ ijaet. 843193 & of a thin lubricant film, which separates the moving surfaces from each \\
\hline $\begin{array}{l}\text { * Corresponding author } \\
\text { bas@ktu.edu.tr }\end{array}$ & $\begin{array}{l}\text { other. Boron compounds, in particular, are very helpful for the sliding } \\
\text { surfaces. The aim of the investigation is to clarify how the boron additives }\end{array}$ \\
\hline Received: Dec 19, 2020 & influence the lubricating ability of the engine oil using in the sliding contact \\
\hline Accepted: Feb 27, 2021 & of the cam-follower. In this study, the considerable results in the tests of \\
\hline Published: Mar 31, 2021 & engine oil with boron compounds and with base oil are obtained. And also, \\
\hline $\begin{array}{l}\text { Published by Editorial Board } \\
\text { Members of IJAET }\end{array}$ & $\begin{array}{l}\text { the influences of the minimize interface friction has been observed under } \\
\text { different test conditions. }\end{array}$ \\
\hline $\begin{array}{l}\text { (c) This article is distributed by } \\
\text { Turk Journal Park System under }\end{array}$ & $\begin{array}{l}\text { Keywords: Additives, Internal Combustion Engine, Lubricant, Boron Compounds, Friction Force, } \\
\text { Friction Coefficient, Boric Acid, Boron Nitride. }\end{array}$ \\
\hline
\end{tabular}

the $\mathrm{CC} 4$.

\section{Introduction}

In many applications like gears, cams, valves, the operating conditions warrant the operation to lie in the mixed lubrication regime[1]. Besides, under very heavy loads, slow relative speed, insufficient surface area and scarcity of lubricant, the formation of the thick film necessary for hydrodynamic lubrication become difficult and interacting surfaces contact each other at several locations and tribo-pairs operate in mixed lubrication. The basic principle of lubrication is to keep an oil film between separated surfaces of the machine part moving relative to each other and to minimize wear. Additives in the lubricant strongly influence the behavior and the operational lifetime of the cam mechanisms. [2]. Ideally, this would be accomplished with an oil film thick enough to eliminate any contact in all internal combustion engine parts and bearings, but this may not be always possible. Therefore, to provide new desirable properties, improve existing features, and eliminate some undesirable features or at least reduce them to a minimum level, some additives are added to the lubricants [3]. In an actual engine, the lubricating oil film thickness will range from a continuous film of oil in hydrodynamic lubrication, as in crankshaft bearings, to a trapped and thinner film in elastohydrodynamic lubrication and boundary or mixed lubrication [4], as in cam-follower mechanisms. Hence, to improve the lubricating ability of the base oil and to make motor oil more slippery, boron-based additives are used with base oil which reduce friction between engine parts in an automobile and thus 
increasing wear resistance [5-7].

Boron compounds have a unique combination of tribological properties and unique ways of interacting with sliding surfaces to provide low friction and wear under both dry and lubricated sliding conditions. In fact, several journal articles provide information on the properties of certain solid lubricants that were mixed with a range of liquid and greases lubricants [8, 9-11]. Without the boric acid particles, the friction coefficient of base oil is around $\sim 0.15$. When base oil is blended with nanoscale boric acid particles, the friction coefficient is reduced to 0.04 . Because of their layered structure, they can shear easily to provide low friction [8]. Hexagonal boron nitride is a well-known lamellar solid lubricant like graphite $[8,12,13]$. In its atomic layers, boron and nitrogen are covalently bonded to one another to form a twodimensional atomic sheet, while bonding between the layers is primarily van der Waals type and weak. The hBN has self-lubricity and can be used for mechanical seals and hightemperature solid lubricants and as padding between metal and ceramic to make bearings. Kimura and his coworkers showed that the addition of $\mathrm{hBN}$ powders into oil at concentrations as low as $1 \mathrm{wt} \%$ significantly reduced wear [7].

Hexagonal boron nitride $(\mathrm{hBN})$ and boric acid stand out as very effective solid lubricants. They are very soft, but due to their unique lamellar structures, they provide some of the lowest friction coefficients in a variety of tribological applications [7,8,14]. In addition, they are generally believed to have little if any detrimental effect on either the machine components or the environment [7]. Specifically, boron compounds have been extensively studied as boundary-lubricating oilsoluble additives, solid lubricants, and surface coatings $[15,16,17]$. Therefore, research on boron-based additives has considerably increased within the last decade. But there are little data currently available on the tribological behavior of base engine oil and boron additives on the cam mechanisms. Thus, two types of boron compounds and their effect on the base engine oil were investigated using the cam and follower mechanism, designed and manufactured in the laboratory. The results can guide the tribological application of engine oil using with different boron compound additives on the cam mechanisms, existing in internal combustion engines and many industrial applications.

\section{Theoretical Bases}

\subsection{Force analysis}

In the cam mechanism, the contact load acting on the cam-follower contact area varies depending on the cam rotation angle. Maximum contact load occurs at cam angles where the cam nose is in contact with the follower.

The loading state of the flat-surface followercam pair is shown in Figure 1. Here, the contact load is in the same direction as the centerline during a cam period due to the flatness of the follower surface. The contact load at the contact surface is constant only along the base circle. The cam surface acts on the follower surface with the cam pressure angle depending on the cam rotation angle. The maximum value of the pressure angle in question occurs in the cam position where the contact point of the two surfaces is furthest from the centerline, as shown in the Fig.1. Thus, the cam remains under the influence of the maximum torque at the rotation angles corresponding to these positions.

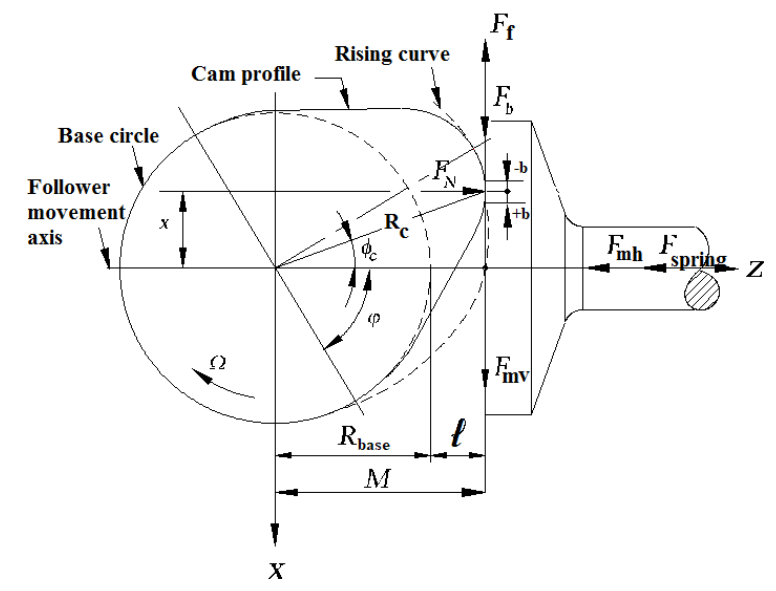

Figure 1: Loading status of flat-surfaced cam-follower pair.

\subsection{Friction Force}

The regime of true mixed lubrication, where there are both elastohydrodynamic and boundary lubricated regions within a single contact, remains quite poorly understood. The cam-follower pair is a very complex lubricated contact because of its continuous variation of load, speed and radius of curvature. In order to determine the friction force arising in the 
elastohydrodynamic contact under the forces acting through a period in the cam mechanism, the calculation process was made as follows.

$$
F_{s}=\ell\left(u_{1}-u_{2}\right) \int_{-b}^{b} \frac{\eta}{h_{c e n}} d x
$$

Where, $\ell$ is cam stroke, $u_{1}$ and $u_{2}$ are velocity components at the $\mathrm{x}$ direction of the contact points of the cam and the follower, $\eta$ is lubricant viscosity, and is given in Equation 2

$$
\eta=\eta_{0} e^{\alpha p}
$$

and hertz pressure distribution at the contact is given with Equation 3

$$
p_{(x)}=p_{(\max )}{\sqrt{1-\left(\frac{x}{b_{H z}}\right)^{2}}}^{2}
$$

Where, $b_{H z}$ and $P_{(\max )}$ are half width and maximum hertz pressure of the elastic line contact. By substituting Equations (2) and (3) in Equation (1), the friction force on the contact of the cam follower can be written as follows.

$F_{S}=\frac{\eta_{0}\left(u_{1}-u_{2}\right)}{h_{c e n}} \cdot \ell \cdot \int_{-b}^{b} e^{\alpha \cdot P_{\max }} \sqrt{\left(1-\frac{x^{2}}{b_{H z}^{2}}\right)} d x$

Where, $h_{c e n}$ is the film thickness at the lubricated contact between cam and follower where the maximum hertz pressure occurs [18]. The integration process encountered in the calculation of the friction force is solved numerically.

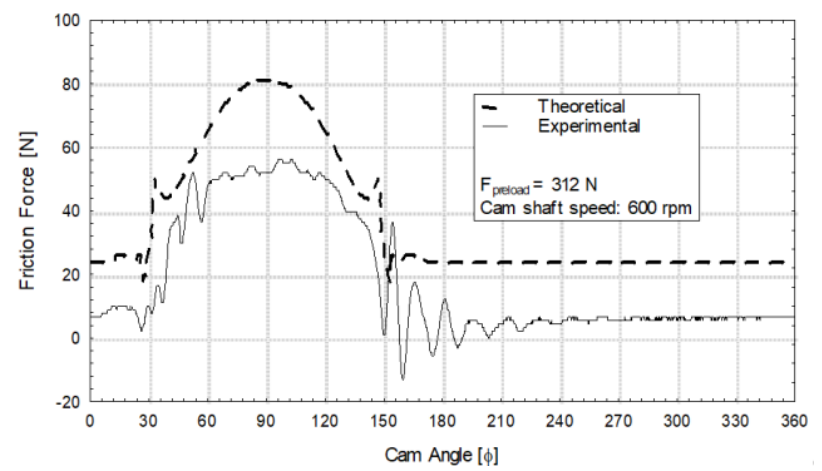

Figure 2: Experimental and theoretical results of the friction force at $312 \mathrm{~N}$ contact load.

It is seen that the results obtained in theoretical and experimental studies are in harmony with each other. However, a slight difference has been observed in the theoretical and experimental friction force graphs, for example, as seen in Figure 2. The reason for this is that the Barus equation, which gives the pressureviscosity relationship in the equation (4) used in the theoretical analysis, gives more values than the actual values of the lubricant behavior of non-conformal contacts under heavy loading conditions [19]. Therefore, many rheological models have been put forward to determine lubricant behavior in elastohydrodynamic contact in lubricant rheology. It has been observed that there are also differences between the theoretical and experimental friction coefficient results obtained from these models [20].

\section{Experimental Setup 3.1. Description of the test rig}

The mechanical system and measurement unit of the test apparatus is designed to measure the frictional behavior between cam and follower at different loads, speeds and lubricating conditions. A lubricating system is designed to investigate the effect of different type of oils on the friction behavior at the cam/ follower interface. In order to ensure safe and accurate data collection and storage, a computer and a data acquisition system are attached to the measurement unit and a computer program is written to evaluate this data.

The test apparatus was manufactured in the Mechanical Engineering Department at Karadeniz Technical University. Detailed information about the test apparatus can be obtained from Ref. [21]. The test apparatus mainly consists of a driving unit, a measurement unit, a cam/ follower system, a loading unit and a lubricating unit as illustrated schematically in Ref. [21]. The camshaft is driven by a $5.5 \mathrm{~kW}$ induction type electric motor whose speed can be changed by a speed control unit in the range of $0-1200 \mathrm{rpm}$. There is a belt-pulley mechanism between the cam shaft and the electric motor and a flywheel is added to the driving shaft to provide a stable rotation of the cam. The flywheel is supported by two ball bearings and connected to the cam shaft via a gear type clutch. The cam shaft consists of a 32 $\mathrm{mm}$-base diameter cam profile and a $7.888 \mathrm{~mm}$ cam stroke which are actual case and is held rigidly to the stationary plate by two journal bearings. A measurement beam for calculating friction force is mounted on a carriage pad, which is rigidly connected to the cylinder. The 
follower is fixed vertically to the measurement beam and applies a preload to the cam surface by means of a spring. The loading of the follower is provided by the spring stroke, which changes via the rotation of cam. The pairs of cam and follower were selected from Mercedes cam and INA follower.

\subsection{Measurement procedures}

To determine the friction force, the balance of forces applied on the follower in the vertical direction should be considered. The friction force applied to the follower by cam, $F_{f}$, causes a tensile effect on the measurement beam $\left(F_{b}\right)$ and the effect produces a signal proportional to the beam force, which can be used in the calculation of the friction force. The balance of forces in the vertical direction applied on the follower can be written as:

$F_{f}=F_{m v}+F_{b}$

where $F_{m v}$ is the mass force of the follower that can be determined by using the following equation:

$F_{m v}=m_{v} a_{v}$

where " $m v$ " and " $a v$ " are mass and acceleration of follower in the vertical direction, respectively. The friction coefficient can then be easily calculated from the well-known Coulomb friction law as:

$\mu=F_{f} / F_{n}$

$F_{n}=F_{\text {spring }}+F_{m h}$

Where $F_{n}$ is the normal force applied on the contact region of the cam/ follower, $F_{\text {spring }}$ is the spring force and $F_{m h}$ is the mass force arising from the moving masses in the horizontal direction. The mass force can be calculated as $\left(F_{m h}=m_{h} \cdot a_{h}\right)$. Where " $\mathrm{m}_{h}$ " is the mass of moving parts in the horizontal direction and " $a$ " is the acceleration. The spring force is, then, calculated from a calibrated spring in terms of the cam stroke. The spring force includes the preloading force and the stroke force of the spring acquired by the reduction in spring length due to cam movement. In this system, a spring having a spring coefficient of $104.7 \mathrm{~N} / \mathrm{mm}$ is used and the calibration equation is Force [N] $=104.7 \cdot \mathrm{x}$ displacement of spring $(\mathrm{mm})$.

In the test apparatus, two types of accelerometers were used to measure the mass force in vertical and horizontal directions due to the acceleration of moving masses. The mass force in the horizontal direction is measured by using a piezoelectric type of accelerometer sensor, which works by a compression effect and is mounted rigidly between two linear bearings in the loading system. This acceleration meter has a voltage sensitivity of $7.43 \mathrm{~V} / \mathrm{ms}^{-2}$ and strain sensitivity of $0.003 \mathrm{~ms}^{-2}$ $/ \mu$ strain in the horizontal direction. An acceleration sensor is used for the calculation of friction force in the vertical direction in order to measure the mass force and mounted below the follower. This sensor has an accuracy factor of $\leq 0.03$. The signals taken from the sensor are amplified by a charge amplifier and are sent to a computer via a data acquisition system. Temperatures of the test samples, on the other hand, were measured with $\mathrm{K}$ type thermocouple. The end of thermocouple connected to specimen, quick and reliable contact temperature readings via functional millivoltmeter is possible.

\subsection{Base oil and boron additives}

Typical physical characteristics of the base oil (20W50 engine oil), used in this study, are given in Table 1. As additives, two kinds of boron compounds hexagonal boron nitride and boric acid powders used. Because of the additive content in the base oil was low, the viscosity variation of oil was neglected.

Table 1: Typical physical characteristics of the base oil

\begin{tabular}{llc}
\hline \multicolumn{1}{c}{ SAE Viscosity Grade } & & $\begin{array}{c}\text { Base Oil } \\
(20 \mathrm{~W} 50)\end{array}$ \\
\hline $\begin{array}{l}\text { Kinematic viscosity } \\
\text { @ } 40^{\circ} \mathrm{C} \mathrm{cSt}\end{array}$ & ASTM D 445 & 688.8 \\
$\begin{array}{l}100^{\circ} \mathrm{C} \mathrm{cSt} \\
\text { Dynamic viscosity }\end{array}$ & \\
$@-25^{\circ} \mathrm{C} \mathrm{mPa} \mathrm{s}$ & ASTM D 5293 & -8.910 \\
$-15^{\circ} \mathrm{C} \mathrm{mPa} \mathrm{s}$ & & \\
Viscosity Index & ASTM D 2270 & 102 \\
Density @ 15 ${ }^{\circ} \mathrm{C} \mathrm{kg} / \mathrm{L}$ & ASTM D 4052 & 0.890 \\
Flash Point COC, ${ }^{\circ} \mathrm{C}$ & ASTM D 92 & 236 \\
Pour Point, ${ }^{\circ} \mathrm{C}$ & ASTM D 97 & -21 \\
\hline
\end{tabular}

\subsection{Test methodology}

To investigate the effects of boron compound additives on the motor base oil, and to determine their optimum ratios, base oil was prepared by addition of $2 \mathrm{wt} . \%, 4 \mathrm{wt} . \%$, $6 \mathrm{wt} . \% \mathrm{HBN}$ and BA and the optimum concentration ratio was 
determined as $4 \mathrm{wt} \%$ for boric acid (H3BO3) and $4 \mathrm{wt} \%$ for hexagonal boron nitride $(\mathrm{hBN})$ [2]. So, in this study, experiments carried out by addition 4wt HBN and BA to the base oil. Samples were tested at various loads and speeds under lubricated conditions. Experiments were conducted at 400, 600 and $800 \mathrm{rpm}$, and 212, $312412 \mathrm{~N}$ contact loads. Experimental periods were selected as 10 minutes for every test after running-in, and the average values of at least three tests were taken.

The measurements were recorded continuously, and the friction force was recorded with the load cell. Temperature of samples was measured with a thermocouple connected to the follower. Tribological properties were determined at $40^{\circ} \mathrm{C}$, in $70 \%$ relative humidity (RH). Both boron compound additives used were $99.9 \%$ pure, and the size of HBN and BA powders was as of 10 and 50 micrometers, respectively. The results were evaluated taking into consideration the forming a tribofilm in mixed or EHD lubrication.

\section{Results and Discussion}

\subsection{Tribological behavior}

Figure 3 shows normal force, friction force and friction coefficient in a cam period lubricated by base oil ((20W50 engine oil) at $312 \mathrm{~N}, 600 \mathrm{rpm}$, $40^{\circ} \mathrm{C}$. It is seen that the minimum contact load between the cam follower is occurred at the cam base circle, called preload value, the minimum contact load increases along with the cam profile and reaches its maximum value at the cam nose i.e. at cam angles around degrees 90.

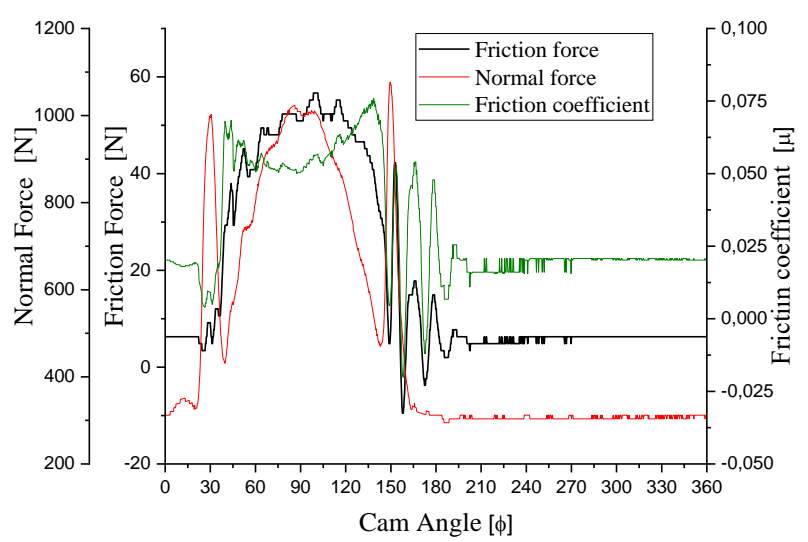

Figure 3: Normal force, friction force and friction coefficient in a cam period lubricated with the base oil

(20W50 engine oil) at $312 \mathrm{~N}, 600 \mathrm{rpm}$ and ${ }^{\circ} \mathrm{C} 40$.

Figure 4 shows the friction force as a function of contact speeds to be able to diagnose the effect of the $\mathrm{hBN}$ additives on the base engine oil (20W50) at 400, 600 and $800 \mathrm{rpm}$. As shown in the Fig. 4, the friction force of the base oil has decreased with the addition of hBN. However, there is a slight difference between the friction force of the base oil and boron compounds of $\mathrm{hBN}$. The friction force of base oil and $+4 \mathrm{wt} \%$ $\mathrm{hBN}$ have a different value. In the tests performed at 400, 600 and 800 cycles, it was observed that the percentage of reduction in friction forces caused by the addition of $4 \% \mathrm{hBN}$ additives to the base oil was $3.5 \%, 5.7 \%$ and $4 \%$, respectively. In order to determine the reduction rates in friction values more precisely, the Distance Weighted method has been applied to the curves in the graphs.

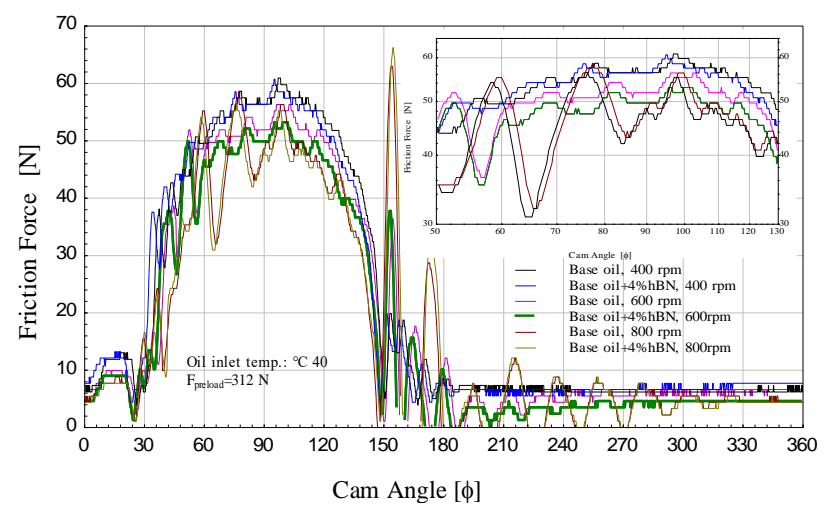

Figure 4: Test results for friction forces at 400, 600 and $800 \mathrm{rpm}$ with the base oil and $4 \% \mathrm{hBN}$.

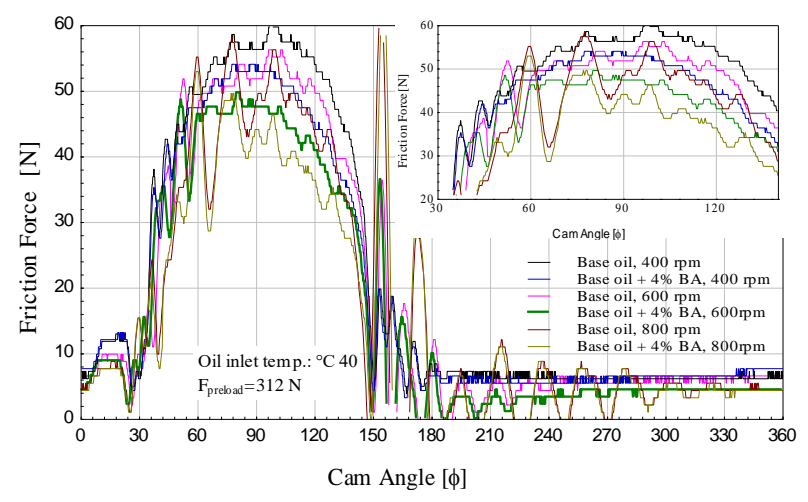

Figure 5: Test results for friction forces at 400, 600 and $800 \mathrm{rpm}$ with the base oil and 4\% BA.

Figure 5 shows the friction force as a function of contact speeds to be able to determine the effect of the BA additive on the base engine oil at 400, 600 and $800 \mathrm{rpm}$. As shown in Fig. 5, the friction force of the base oil was decreased with the addition of BA boron compound. However, there is a more difference between the friction force of the base oil and BA compound than that of hBN. Indeed, at 400, 600 and 800 cycles, it was observed that the percentage of reduction in 
friction forces caused by the addition of $4 \% \mathrm{BA}$ additive to the base oil was $10 \%, 15 \%$ and $11 \%$, respectively.

Furthermore, in order to investigate the effect of contact load on friction force in base oil, $4 \%$ $\mathrm{hBN}$ and $4 \% \mathrm{BA}$, the tests performed at two preload values, $\left(\mathrm{F}_{\text {preload }}=212 \mathrm{~N}\right.$ and $\left.412 \mathrm{~N}\right)$. As shown in Fig. 6, it was observed that, reducing effect on the friction, addition of $4 \% \mathrm{hBN}$ and $4 \%$ BA compounds to the base oil, was $7 \%$ and $12 \%$ at $212 \mathrm{~N}$ preload, and $7.7 \%$ and $13.2 \%$ at $412 \mathrm{~N}$ preload, respectively. These results indicate that the friction reduction effects of boron additives on the contact loads exist, and these additives improved the antiwear property of base engine oil. The results obtained are consistent with those of Shah [5] and Baldwin [6]. It's clearly seen that the boric acid additive has more influence than that of hexagonal boron nitride additive in reducing friction force, and this influence increased with increasing contact load at $40^{\circ} \mathrm{C}$, as shown in Fig. 6 .

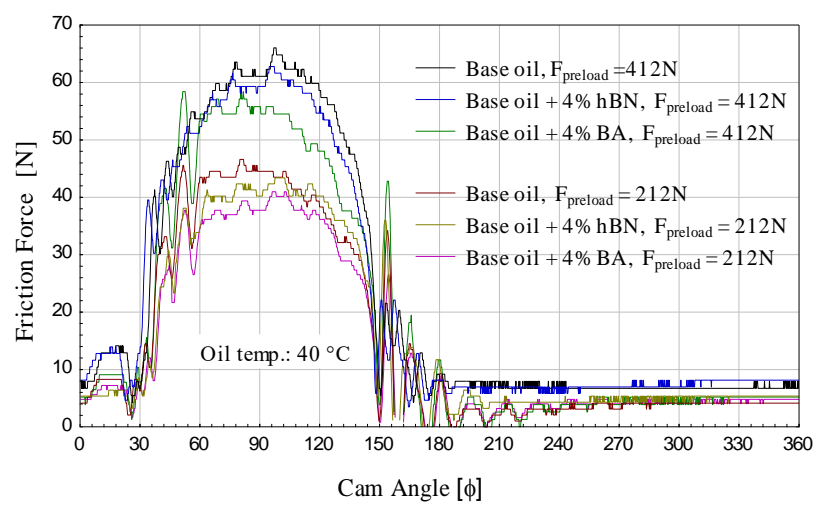

Figure 6: Effect of load on friction force in base oil, 4\% $\mathrm{hBN}$ and $4 \%$ BA tests.

\section{Conclusion}

Contact loads of the cam and follower were 212, 312 and $412 \mathrm{~N}$, respectively. These were very near Hertzian pressure becomes in EHL, and contact surface non-conformal. Therefore, the system may be evaluated in a mixed lubrication regime, and local micro EHL zones may form at the interface of roughness surfaces. Local micro EHL zones and micro contact of the roughness surfaces affects the friction coefficient seriously. Especially, the formation of tribofilm in micro scale can reduce friction coefficient in the boundary or mixed lubrication. Furthermore, the tribofilm reduces the effect of micro EHL and micro contact of the surface roughness. From the above experimental results, following conclusions can be drawn:

- In engine parts, especially on the cam and follower, boron compound additives can reduce friction force seriously, forming a tribofilm, in the boundary or mixed lubrication conditions.

- The reduction of friction force, especially at high speeds, and high loads was observed.

- The effect of boron compound additives on the friction force rises with increasing of contact load and speeds.

- $\quad$ Effect on friction force of BA and hBN on the pair of contact was very close to each other. But the effect of boric acid additive was better than that of hBN.

Boric acid additives have more influence than that of hexagonal boron nitride additive in reducing friction force, and this influence was increased with increasing contact load.

\section{Acknowledgment}

This research was funded by the Karadeniz Technical University, Scientific Research Projects Unit, (Project Code: 2008.112.003.9). Also, author would like to thanks to National Boron Research Institute for supporting of boron compounds.

\section{References}

1. H. Hirani, Mixed Lubrication. In Fundamentals of Engineering Tribology with Applications (pp. 326-370). Cambridge: Cambridge University Press. 2016.

2. H. Bas and Y. E. Karabacak, "Investigation of the Effects of Boron Additives on the Performance of Engine Oil," Tribology Transactions, 57:4, 740-748, 2014.

3. T. Bartels, "Lubricants, 5. Gear Lubrication Oils", Ullmann's Encyclopedia of Industrial Chemistry, ISBN: 9783527306732, 2011.

4. J. M. Herdan, "Friction modifiers in engine and gear oils", Lubrication. Science, 12, 3, pp. 265-276, 2000.

5. F. U. Shah, "Boron Compounds as Additives to Lubricants, Synthesis, Characterization and Tribological, Optimization", Lulea University of technology, 2009.

6. B. A. Baldwin, "Relative antiwear efficiency of boron and sulphur surface 
species", Wear, 45, 3, pp. 345-353, 1977.

7. Y. Kimura, T. Wakabayashi, K. Okada, T. Wada, and H. Nishikawa, "Boron nitride as a lubricant additive", Wear, 232, 199, pp. 206.56, 1999.

A. Erdemir, "Advances in Boron-Based Lubricants and Lubrication Additives", IV International Boron Symposium, October Eskisehir, Turkey, 2009.

8. F. Chinas-Castillo and H. A. Spikes, "Mechanism of action of colloidal solid dispersions", J. Tribology-Trans., ASME, 125, 3 pp. 552-557, 2003.

9. P. J. Pacholke and K. M. Marshek, "Improved worm gear performance with colloidal molybdenum-disulfide containing lubricants", Lubr. Eng., 43, pp. 623-628, 1987.

10. R. S. Barnett, "Molybdenum disulfide as an additive for lubricating greases", Lubr. Eng., 33, 308-313, 1977.

11. Erdemir, "Solid lubricants and selflubricating films, in "Handbook of Modern Tribology," B. Bhushan, ed., CRC Press, Boco Raton, FL, pp. 787-818, 2001.

12. G.W Rowe, "Some observations on the frictional behaviour of boron nitride and of graphite", Wear, 3, 4, pp. 274-285, 1960.

13. J. M. Martin, T. LeMogne, C. Chassagnette, and M. N. Gardos, "Friction of hexagonal boron nitride in various environments", Tribol. Trans., 35, 463-472, 1992.

14. C. C. Klepper, J. M. Williams, J. J. J. Truhan, J. Qu, L. Riester, R. C. Hazelton, J. J Moschella, P. J. Blau, J. P. Anderson, O. O. Popoola and M. D. Keitz "Tribomechanical properties of thin boron coatings deposited on polished cobalt alloy surfaces for orthopedic applications", Thin Solid Films, 516, 10, pp. 3070-3080, 2008.

15. M. Lovell, C. F. Higgs, P. Deshmukh and A. Moble, "Increasing formability in sheet metal stamping operations using environmentally friendly lubricants", J. Mat. Pro.Tech. 177, pp. 87-90, 2006.

16. J. H. Wu, B. S. Phillips, W. Jiang, J. H. Sanders, J. S. Zabinski, and A. P. Malshe, "Bioinspired surface engineering and tribology of MoS2 overcoated cBN-TiN composite coating”, Wear, 261, pp. 592-599, 2006.

17. H. U. Jamali, A. Al-Hamood, O.I. Abdullah, A. Senatore and J. Schlattmann,
"Lubrication Analyses of Cam and Flat-Faced Follower," Lubricant, 7, 31, 2019.

18. C. M. Taylor, "Valve train lubrication analysis. Seventeenth Leeds-Lyon Symposium on Tribology_vehicle tribology, Tribology Series 18, pp. 119-131 (Elsevier, Oxford). 1991.

19. H. A. Spikes, V. Anghel and R. Glovnea, "Measurement of the Rheology of Lubricant Films Within Elastohydrodynamic Contacts" Tribology Letters, 2014.

20. H. Bas, Ph.D. Thesis, "Investigation of Friction Behavior of Additive Engine Oils on Cam Mechanisms,"Karadeniz Technical University Institute of Natural and Applied Sciences, 2001. 